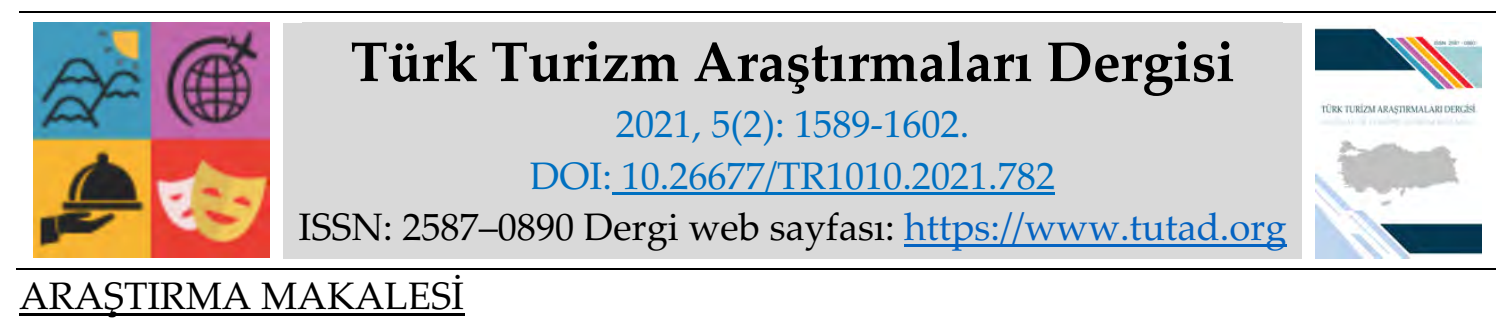

\title{
İklim Değişikliği ve Gıda Güvenliği Konulu Hakem Denetimli Makalelerin Bibliyometrik Profili
}

Arş. Gör. Aykut Göktuğ SOYLU, Mersin Üniversitesi, Turizm Fakültesi, Mersin, e-posta: soyluaykut93@gmail.com

ORCID: https://orcid.org/0000-0002-7402-2291

Prof. Dr. Fügen DURLU ÖZKAYA, Ankara Hacı Bayram Veli Üniversitesi, Turizm Fakültesi, Ankara, e-posta: fugen.ozkaya@hbv.edu.tr

ORCID: https://orcid.org/0000-0003-2893-9557

\section{Öz}

Çalışmanın amacı iklim değişikliği ve gıda güvenliği konulu hakem denetimli makalelerin bibliyometrik profilini ortaya koymaktır. Bu amaç doğrultusunda çeşitli veri tabanları üzerinden erişim sağlanan 32 makale değerlendirilmeye alınmıştır. Veri tabanları üzerinden yapılan tarama sırasında iklim değişikliği ve gıda güvenliği terimleri hem anahtar kelime hem de başlık bazında birlikte kullanılmıştır. Araştırma sonucunda erişilebilen ilk makalenin 2009 yılında olduğu tespit edilmiştir. İklim değişikliği ve gıda güvenliği konulu makalelerin en çok 2013-2015 yılında yayımlandığı sonucuna ulaşılmıştır. Makalelerin çoğunluğunun kavramsal araştırmalarından oluştuğu, çalışmalarda genellikle 0-50 atıf aralığında atıf yapıldığı, çalışmaların genel olarak 0-10 sayfa aralığında olduğu tespit edilmiştir. Makalelerde en çok kullanılan anahtar kelimelerin iklim değişikliği ve gıda güvenliği olduğu, makalelerin en çok Food Research International dergisinde yayımlandığı ve makalelerin yayımlandıkları dergilerin en çok yiyecek içecek alanında yayım yaptığı tespit edilmiştir. Alana katkıda bulunan yazarların kurumları incelendiğinde, en çok Wageningen University ve Chung-Ang University kurumlarında çalışan yazarların katkıda bulunduğu görülmektedir. Sonuç olarak araştırmacıların iklim değişikliği ve gıda güvenliği konulu yayımlara az ilgi gösterdikleri söylenebilir. Ayrıca, araştırmacılara gıda güvenliği ve iklim değişikliği konularını birlikte düşünerek çalışmalarına yön vermeleri önerilmektedir.

Anahtar Kelimeler: İklim Değişikliği, Gıda Güvenliği, Bibliyometri.

Makale Gönderme Tarihi: 27.02.2021

Makale Kabul Tarihi: 04.06.2021

\section{Önerilen Atıf:}

Soylu, A. G. ve Durlu Özkaya, F. (2021). İklim Değişikliği ve Gıda Güvenliği Konulu Hakem Denetimli Makalelerin Bibliyometrik Profili, Türk Turizm Araştırmaları Dergisi, 5(2): 1589-1602.

(C) 2021 Türk Turizm Araştırmaları Dergisi. 


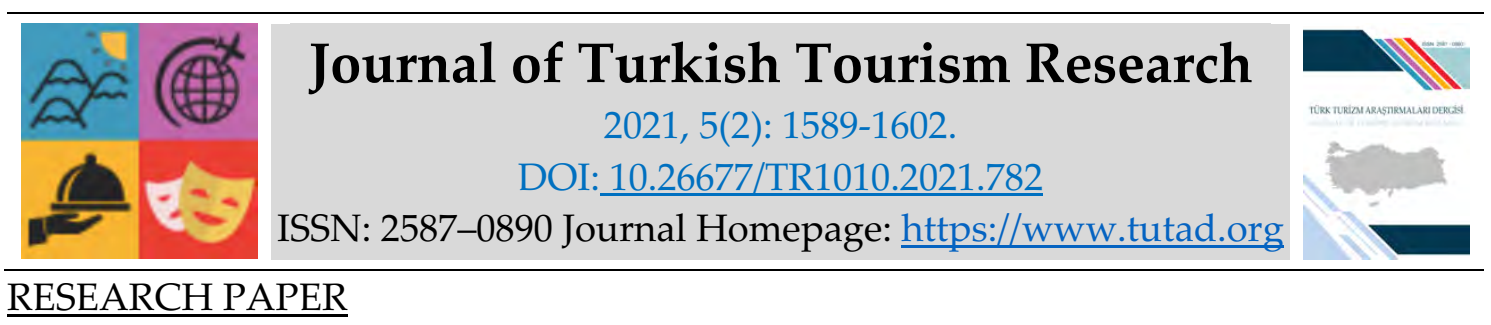

Bibliometric Profile of Peer-Reviewed Articles on Climate Change and Food Safety

Research Assistant Aykut Göktuğ SOYLU, Mersin University, Faculty of Tourism, Mersin, e-mail: soyluaykut93@gmail.com

ORCID: https://orcid.org/0000-0002-7402-2291

Prof. Dr. Fügen DURLU ÖZKAYA, Ankara Hacı Bayram Veli University, Faculty of Tourism, Ankara, e-mail: fugen.ozkaya@hbv.edu.tr

ORCID: https://orcid.org/0000-0003-2893-9557

\begin{abstract}
The aim of the study is to reveal the bibliometric profile of peer reviewed articles on climate change and food safety. For this purpose, 32 articles accessed through various databases were evaluated. During browsing through databases, the terms climate change and food safety were used together on both keyword and title basis. As a result of the research, it was determined that the first article to be accessed was in 2009. It is concluded that articles on climate change and food safety were published most in 2013-2015. It was determined that the majority of the articles consisted of conceptual researches, the studies were generally cited in the 0-50 citation range, and the studies were generally in the 0-10-page range. It has been determined that the most used keywords in the articles are climate change and food safety, the articles are published mostly in Food Research International magazine and the journals in which the articles are published mostly in the field of food and beverage. When the institutions of the authors who contributed to the field are examined, it is seen that the authors who work at Wageningen University and ChungAng University institutions mostly contribute. As a result, it can be said that researchers show little interest in publications on climate change and food safety. In addition, researchers are advised to direct their studies by considering food security and climate change issues together.
\end{abstract}

Keywords: Climate Change, Food Safety, Bibliometric.

Received: 27.02.2021

Accepted: 04.06.2021

\title{
Suggested Citation:
}

Soylu, A. G. and Durlu Özkaya, F. (2021). Bibliometric Profile of Peer-Reviewed Articles on Climate Change and Food Safety, Journal of Turkish Tourism Research, 5(2): 1589-1602.

(c) 2021 Türk Turizm Araştırmaları Dergisi. 


\section{GİRIŞ}

Bibliyometri terimi Latince kitap anlamına gelen "biblio" ve ölçü biri anlamına gelen "metrics" kelimelerinin birleşiminden oluşmaktadır. Bibliyometrinin bilimsel araştırmalarda kullanımı 19. Yüzyılın sonlarından itibaren görülmekle birlikte terim olarak ilk defa 1969 yılında kullanılmaya başlanmıştır (Sengupta, 1992). Bibliyometri terimi ilk kez 1969 yılında "The Journal of Documantation" isimli dergide Alan Pritchard tarafından "Statistical bibliography or bibliometrics" adlı makalede kullanılmıştır (Altürk, 2018). Pritchard (1969)'a göre bibliyometri, "matematik ve istatistiksel yöntemlerin kitaplara ve diğer yazılı iletişim araçlarına uygulanması" dır. Ancak bibliyometrik araştırmaların tarihinin çok daha eskilere dayandığını savunan görüşler de mevcuttur. Bibliyometri terimi literatüre kazandırılmadan önce yöntem "istatistiksel bibliyografi" olarak kullanılmaktaydı. "statistical" ve "bibliography" (Webster's, 1985: 148) kelimelerinin birlikte kullanılması sonucu oluşan "statistical bibliography"'nin istatistiki yöntemler vasıtası ile oluşturulmuş bibliyografya olduğu söylenebilir (Altürk, 2018). Bununla birlikte Shapiro (1992), 18. yüzyıla kadar atıf dizinlerinin kullanımının görüldüğünü ve yayım sayımının en az 1800'lerde başladığını belirtmektedir. Bibliyometri örneklerinin, terimi kullanan Pricthard'dan çok daha önce var olduğunu savunmaktadır. Ancak konunun bilgi bilim tarihçileri tarafından ihmal edildiğini ileri sürmektedir. Başlangıcı ile ilgili tartışmalar günümüzde devam etmekle birlikte bibliyometrik araştırmalar, ilgili alandaki literatürün nicelleştirilmesi ve tespit edilen kavramların değerlendirilmesi ile alandaki genel eğilimlerinin ne yönde olduğunun görülmesi bakımından önemlidir (Kasemodel Makishi, Souza ve Silva, 2016; Güzeller ve Çeliker, 2017). Öte yandan çalışmaların tarihsel gelişimi, çalışma alanındaki genel gidişatın da belirlenmesine yardımcı olmaktadır (Barrios, Borrego, Vilagines, Olle ve Somoza, 2008). Sonuç olarak bibliyometrik çalışmalar, kitap ve dergilerde ulusal ve uluslararası araştırmaların kullanımını, tarihsel olarak gelişimini, kitap ile dergilerin genel kullanımını belirlemek için, kitap ve süreli yayımlarla ilgili istatistiklerin bir araya getirilmesi ve işlenmesidir (Sengupta, 1992). Böylelikle bibliyometrik çalışmalar bir bilimsel alanın geçmişten günümüze gelişimi ve geleceğe yönelik izdüşümlerini ortaya koymaya yarayan, ayrıca verilerin düzenli bir hale getirilmesi ve sınıflandırılmasını sağlayan çalışmalar olarak bilinmektedir (Şahin, Akdağ, Çakıcı ve Onur, 2018).

İklim değişikliği hava koşullarının on yıllardan milyon yıllara varan süreler aralığındaki değişimidir. İklim değişikliği ve küresel ısınma dünya yüzeyindeki bin yıllık sıcaklık ortalamasındaki gözlenen artışı ifade etmektedir. Uzun zaman periyodları içerisinde radyasyon, kıtaların hareketleri, volkanik faaliyetler gibi olaylar iklim değişikliğine sebep olmaktadır. Ancak son on yıllarda fosil yakıtların tüketimi, nüfusun hızlı artışı, kirlilik, endüstriyelleşme gibi insan etkilerinin dünyanın iklimi üzerindeki etkisini çok arttırdığ belirlenmiş ve bu durum küresel ısınma olarak adlandırılmıştır. Hükümetler arası İklim Değişikliği Paneli, iklim değişikliği 2014 raporunda küresel ısınmanın \%95 oranında insanlar sebebi ile oluştuğunu belirtilmektedir (IPCC, 2014). İklim değişikliğinin potansiyel etkileri incelendiğinde; deniz seviyesinde buzulların erimesi nedeniyle su seviyesinde yükselme ve bunun sonucu olarak ekonomik ve sosyal riskler, enerji tüketimindeki değişimler, sıtma gibi salgınlarda artış, tarım yapılabilir alanların azalması ve açlık, doğal çevrenin bozulması ve temiz su kaynaklarına erişim gibi riskler barındırdığ görülmektedir (EC-DGE, 2005). Bu nedenle iklim değişikliği konusu bilim insanları açısından giderek önemli hale gelmeye başlamıştır. Fen bilimcilerin yanı sıra sosyal bilimciler iklim değişikliğinin hali hazırda ve olası etkilerini ve risklerini kişi ve toplum bazında ekonomik, politik ve çevresel bağlamda incelemektedirler (Haunschild, Bornmann ve Marx, 2016).

Gıda güvenliği, sağlıklı gıda üretimini sağlamak için gıdaların üretim, işleme, depolama, taşıma ve dağıtım aşamalarında gerekli sağlık kurallarına uyularak önlemlerin alınması olarak tanımlanmaktadır. Bununla birlikte sağlıklı, hijyenik ve insan sağlığına faydalı ve sağlıklı 
durumu korunan gıdaları ifade etmektedir (Ceyhun Sezgin, 2020). Gıda güvenliğini küresel ölçekte etkileyen sosyo-ekonomik ve teknolojik gelişmeler, şehirleşme, tarım arazilerinin kullanımı, küresel ticaret gibi pek çok faktör bulunmaktadır. İklim değişikliği ve beraberinde getirdiği etkiler ise doğanın değişimine ve böylelikle gıda güvenliğini etkileyen faktörlerin artmasına veya değişmesine sebep olmaktadır. Gıda güvenliğine etki eden faktörler gida tedarik zincirinin üretim ve tüketim aşamaları arasında herhangi bir noktada ortaya çıkabilmektedir. İklim değişikliği bu tip sorunların ya tetikleyicisi ya da direkt sebebi olabilmektedir. Gıda güvenliğine etki eden faktörlere hava sıcaklığındaki dalgalanmalar, aşırı hava olayları, okyanus ve denizlerin 1sınması ve asitlenmesi, bakteri, virüs, parazit ve mantarların hava sıcaklarındaki ve yağışlardaki değişimler nedeni ile direnç kazanması örnek olarak verilebilir (Tirado, Clarke, Jaykus, McQuatters ve Frank, 2010).

\section{LITERATÜR TARAMASI}

Konu ile ilgili yapılan çalışmalar incelendiğinde; Shen, Wei ve Sheng (2021) gerçekleştirdikleri çalışmada, 1999-2019 yılları arasında gıda güvenliği yönetişimi çalışmalarını bibliyometrik analize tabi tutmuşlardır. Toplamda 740 makale üzerinden gerçekleştirilen analiz sonuçlarına göre, gıda güvenliği yönetişimi konusunun çevre bilimi, gıda bilimi, ekonomi ve tarım konularını içeren disiplinler arası bir konu olduğu belirtilmiştir. Amerika Birleşik Devletleri'nin konu hakkında en çok makaleye sahip ülke olduğu, Wageningen Üniversitesi'nin ise en çok yayım yapan üniversite olduğu sonucuna ulaşılmıştır. Food Policy dergisinin yayım sayısı ve atıf sıklığı açısından ilk sırada yer aldığı tespit edilmiştir. Gıda güvenliği yönetişimi çalışmalarının içeriğine bakıldığında, düşük ve orta gelirli ülkelerde yapılan çalışmaların daha çok gıda tedariki ve gıda sistemi tasarımına odaklandıkları, daha gelişmiş ülkelerin ise gıda güvenliği ve beslenmeye odaklandıkları görülmüştür. Bununla birlikte gelişmiş ülkelerde yapılan araştırmalarda sıklıkla tüketiciler üzerinde çalışmalar yürütüldüğü de araştırma sonuçları arasındadır.

Wahyuni, Vanany ve Ciptomulyono (2019) yaptıkları çalışmada, gıda tedarik zincirinde gıda güvenliği ve helal gıda konulu araştırmaların bibliyometrik incelemesini gerçekleştirmişlerdir. Araştırmada 120 makale incelemeye alınmıştır. Araştırma sonuçlarına göre, Food Control dergisinin gıda tedarik zincirinde gıda güvenliği konusunda en çok yayım kabul eden dergi olduğu tespit edilmiştir. Food and Drug Admisnistration of United States kurumu ilgili konu hakkında en çok yayım yapan kuruluştur. Kullanılan anahtar kelimeler incelendiğinde sık karşılaşılan anahtar kelimenin gıda güvenliği olduğu sonucuna ulaşılmıştır. Gıda tedarik zincirinde gıda güvenliği makaleleri üzerinde yapılan kümeleme analizi sonucunda anahtar kelimelerin dört kümeye ayrılığı tespit edilmiştir. İlk kümenin gıda zincirindeki risk faktörlerinin yönetilmesi ve buna bağlantılı olarak HACCP ile ilgili olduğu, ikinci kümenin gıda tedarik zincirindeki tehlikelerin önlenebilmesi adına izleme sistemleri kurma ve geliştirme ile ilgili olduğu, üçüncü kümenin gida güvenliğinde kontaminasyon ve buna bağlı olarak hastalık risklerini azaltmak ile ilgili olduğu, dördüncü kümenin ise gıda güvenliği bağlamında sebze ve meyvelerin korunması, saklanması ve taşınması ile ilgili olduğu söylenmektedir.

Polat, Düzgün ve Yeşiltaş (2019) gerçekleştirdikleri çalışmada iklim değişikliğinin turizme etkisini belirlemeye yönelik olarak lisansüstü tezlerin bibliyometrik analizini yapmışlardır. Araştırmada 14'ü yüksek lisans, 24'ü doktora tezi olmak üzere 38 tez incelemeye dâhil edilmiştir. Konuya dair en fazla tezin 2012 yılında yazıldığı, en fazla yayım yapan kurumun İstanbul Üniversitesi olduğu, yabancı lisansüstü tezlerin en fazla Amerika Birleşik Devletleri'nde gerçekleştirildiği ve konu olarak en fazla tezin iklim değişikliğinin turizm sektörüne etkisi konusunda yazıldığı bulgulanmıştır. Araştırma sonuçlarına göre, turizm işletmelerinin iklim değişikliğine yönelik adaptasyon stratejileri, iklim değişikliğinin bir destinasyondaki turizm 
gelişimi, turizm talebi ve turistlerin destinasyon sadakatine etkisi gibi konularda eksiklik olduğu ve araştırma yapılmasına ihtiyaç duyulduğu belirtilmiştir.

Haunschild, Bornmann ve Marx (2016), gerçekleştirdikleri çalışmada iklim değişikliği çalışmalarının bibliyometrik profilini incelemişlerdir. 1980 ve 2014 yılları arasında toplam 222,060 çalışmayı kapsayan araştırma sonuçlarına göre, toplam makale sayısının her 5-6 yılda bir ikiye katlanarak güçlü bir artış gösterdiği belirtilmiştir. Küresel ısınmanın adaptasyonu, hafifletilmesi, riskleri ve güvenlik açığını ele alan araştırmaların diğer ilgili araştırma konularına göre paylarının nispeten küçük olduğu ancak 2005 yılından sonra hatırı sayılı bir artış gösterdiği tespit edilmiştir. İklim değişikliği konusunun doğa bilimlerinin ötesindeki disiplinlerde de bir sorun haline geldiği belirtilmiştir. The Journal of Geophysical Research, the Journal of Climate, the Geophysical Research Letters ve Climatic Change dergilerinin iklim değişikliği konusunda en fazla yayım kabul eden dergiler olduğu belirlenmiştir. İklim değişikliği konusunda Amerika Birleşik Devletleri'nin en fazla makaleye sahip olan ülke olduğu ve bunu Büyük Britanya, Almanya ve Kanada'nın izlediği tespit edilmiştir. Atıf bazlı etki incelendiğinde, Büyük Britanya, Danimarka ve Hollanda'da yapılan yayımların en çok atıf alan yayımların yapıldığı ülkeler olduğu görülmüştür. Yapılan başlık analizi sonucunda "iklim" kelimesinin en çok kullanılan kelime olduğu bunun yanı sıra "etki" kelimesinin de zaman içerisinde çok yüksek sayılarda kullanıldığı sonucuna ulaşılmıştır.

Sweileh (2020a), gerçekleştirdiği çalışmada bulaşıcı hastalıklar bağlamında iklim değişikliği ve insan sağlığı konulu makaleleri bibliyometrik analize tabi tutmuştur. 1980 ve 2019 yılları arasında toplamda 4247 yayım sağlıkla ilgili ve 1207 yayım ise enfeksiyon ile ilgili olarak incelenmiştir. Araştırma sonuçlarına göre yayımların 2007 yılından sonra büyük bir artış gösterdiği görülmüştür. Araştırmada toplamda dört ayrı kategori ortaya çıarılmıştır. Birinci kategori iklim değişikliği ve bulaşıcı hastalıklar, ikinci kategori, iklim değişikliği, halk sağlığı ve gıda güvenliği, üçüncü kategori sıcak hava dalgaları, ölüm oranları ve bulaşıcı olmayan hastalıklar ve dördüncü kategori iklim değişikliği, hava kirliliği, alerji ve solunum sağlı̆̆ olarak tespit edilmiştir. Araştırmaya göre enfeksiyonla ilgili literatürde en sık karşılaşılan bulaşıcı hastalıkların sıtma ve dang humması olduğu tespit edilmiştir. Sağlıkla ilgili literatüre en çok katkı yapan ülkenin Amerika Birleşik Devletleri olduğu belirlenmiştir.

Sweileh (2020b), gerçekleştirdiği çalışmada iklim değişikliği bağlamında gıda güvencesi konulu makaleleri bibliyometrik analize tabi tutmuştur. 1980-2019 yılları arasında toplamda 5960 yayım incelenmiştir. Araştırma sonuçlarına göre, hem yayım hem de atıf sayısı bakımından son on yılda büyük bir yükseliş olduğu belirtilmektedir. En çok kullanılan anahtar kelimelerin iklim değişikliği, gıda güvencesi, kuraklık, adaptasyon, tarım ve su kıtlığı olduğu tespit edilmiştir. Çalışmalarda, su güvenliği, tohum hasadı, gıdaya erişilebilirlik ve sağlık olmak üzere dört ana tema bulunduğu görülmüştür. Amerika Birleşik Devletleri'nin en fazla makaleye sahip olan ülke olduğu bunula birlikte Fransa ve Hollanda'nın da uluslararası yazarların bulunduğu en yüksek belge yüzdesine sahip ülkeler olduğu tespit edilmiştir.

Wu, Geng, Tian, Zhong, Wu, Yu ve Xiao (2018) gerçekleştirdikleri çalışmada iklim değişikliği bağlamında kentsel çevre yönetişimi ile ilgili yayımları bibliyometrik analize tabi tutmuşlardır. Araştırmada 1997 ve 2017 yılları arasında yayımlanan toplam 1697 makale incelenmiştir. Araştırma sonuçlarına göre yayım sayısının yıllara göre kademeli olarak artış gösterdiği belirtilmiştir. Journal of Cleaner Production ve Sustainability and Energy Policy dergileri en çok yayım kabul eden dergiler olduğu tespit edilmiştir. Amerika Birleşik Devletleri en çok yayıma ve yazara ev sahipliği yaparken, Çin Halk Cumhuriyeti ve İngiltere'nin de başı çekmekte olduğu ifade edilmiştir. Ayrıca, sera gazı emisyonu, enerji, su, sağlık ve ulaşımın en çok kullanılan anahtar kelimeler olduğu belirtilmiştir. Araştırma yöntemleri açısından yaşam döngüsü değerlendirmesi ve ekolojik ayak izi araştırmalarının sıklıkla kullanıldığı bulgulanmıştır. 
Wang, Zhao ve Wang (2018) gerçekleştirdikleri çalışmada iklim değişikliğine uyum ile ilgili yayımları bibliyometrik analiz yöntemi ile incelemeye almışlardır. Araştırma kapsamında 1986 ile 2016 arasındaki toplam 14891 yayım incelenmiştir. Araştırma sonuçlarına göre iklim değişikliğine uyum ile ilgili yayımların büyük bir yükseliş trendine girdiği belirtilmiştir. Amerika Birleşik Devletleri'nin yayım bakımından ilk sırada yer aldığı tespit edilmiştir. En fazla yayım kabul eden derginin Climate Change, en fazla yayıma sahip yazarın Kanadalı Ford JD ve en fazla yayımı bulunan kurumun Çin Bilim Akademisi olduğu ifade edilmiştir. Araştırmada ilgili alandaki işbirliğinin güçlenmesine rağmen ulusal düzeyde yayım sayılarının düşük olduğu söylenmektedir. Ayrıca, anahtar kelimelerin analizine göre iklim değişikliği, uyum, kırılganlık, ekosistem, sosyo-ekonomik sistem, tarım, bölge, ekstrem durumlar, hafifletme ve sürdürülebilirliğin en çok kullanılan anahtar kelimeler olduğu tespit edilmiştir. Kırılganlığın anahtar kelimeler arasında temel bir rol oynadığı belirtilmiştir.

Zyoud ve Fuchs-Hanusch (2020) gerçekleştirdikleri çalışmada Arap bilim dünyasındaki iklim değişikliği çalışmalarını bibliyometrik analiz ile incelemişlerdir. Scopus veri tabanı üzerinde taranan toplam 2074 yayım incelenmiştir. Araştırma sonuçlarına göre Arap bilim dünyasının, toplam iklim değişikliği makalelerinin \%1,2'sini ürettiği belirlenmiştir. Suudi Arabistan'ın toplam yayımların \%22,8'ine sahip olarak en fazla yayım üreten ülke konumunda olduğu ayrıca, etki indeksi ve toplam atıf sayısında da başı çeken ülke olduğu belirtilmiştir. Arap bilim dünyası ile Amerika Birleşik Devletleri ve Fransa'nın en fazla bütünleşik çalışma yapan ülkeler olduğu bulgulanmıştır. Plos One ve Arabian Journal of Geosciences dergilerinin en fazla yayım kabul eden dergiler olduğu ifade edilmiştir. Suudi Arabistan'daki üç kurumun en fazla yayım yapan kurumlar olduğu bulgulanmıştır.

\section{YÖNTEM}

\section{Araştırmanın Amacı ve Araştırma Soruları}

Araştırmanın amacı, literatürdeki iklim değişikliği ve gıda güvenliği konulu hakemli dergi yayımlarının bibliyometrik profillerini ortaya çıarmaktadır. Literatürde İklim değişikliği veya gıda güvenliği ile ilgili ayrı ayrı pek çok bibliyografik çalışma bulunmaktadır. Ancak literatürde bu iki konuyu bir arada işleyen çalışmaların bibliyometrik analizine rastlanılmamıştır. Bu durum araştırmanın özgünlügünü ortaya koymaktadır. İklim değişikliği ve gida güvenliği literatürünün bibliyometrik profilinin ortaya konulması adına aşağıdaki araştırma soruları belirlenmiştir. Araştırma sorularının belirlenmesinde (Çiçek ve Kozak, 2012; Yılmaz, 2017; Altürk 2018; Şahin ve diğerleri, 2018)'nin çalışmalarından yararlanılmıştır. Toplanan veriler, istatistik paket programına aktarılarak araştırma sorularına uygun bir şekilde analiz edilmiştir.

- Makalelerin yayımlandığı yıllara göre dağılımı nedir?

- Makalelerin yayımlandığı dergilere göre dağılımı nedir?

- Dergilerin yayım alanlarına göre dağılımı nedir?

- Makalelerin araştırma yaklaşımlarına göre dağılımı nedir?

- Makalelerin anahtar kelimelerine göre dağılımı nedir?

- Makalelerin sayfa sayısına göre dağılımı nedir?

- Makalelerin yapılan atıflara göre dağılımı nedir?

- Makalelerin veri toplama yöntemine göre dağılımı nedir?

- Makalelerin örneklem grubuna göre dağılımı nedir?

- Makalelerin verilerin toplandığı ülkelere ve şehirlere göre dağılımı nedir?

- Makalelerin çok yazarlılık açısından durumu nedir?

- Yazarlarının çalıştı̆̆ kurumlara göre dağılımı nedir 


\section{Araştırmanın Yöntemi}

Çalışmada bibliyometrik yöntem kullanılarak iklim değişikliği ve gıda güvenliği konuları ile ilgili mevcut durumun ortaya konulmasına çalışılmıştır. Bibliyometri, alanda yapılmış çalışmaların çeşitli parametreler bağlamında istatistik analizler aracılığı ile inceleyerek alanın mevcut durumunu belirlemeye yöneliktir. Böylelikle bibliyometrik yöntem aracılığı ile elde edilen bulgular incelenen literatürün gelişimi ve popüler eğilimlerin tespitinde ve ortaya çıkan güncel sorunları belirlenmesinde kaynak olabilmektedir (Altürk, 2018). Çalışma kapsamına sadece makalelerin dâhil edilmesinin nedeni; makalelerin bilimsel gelişmelerin izlenebilmesi ve değerlendirilebilmesi açısından önemli bir kaynak olmalarından ileri gelmektedir. Bu bağlamda gıda güvenliği ve iklim değişikliği ile ilgili makaleler çeşitli veri tabanları (EBSCO Host, JSTOR, SageJournal, Scopus, Springer Link, Wiley Online Library gibi) üzerinden taranmış (Yılmaz, 2017) ve 32 makaleye erişilmiştir. Çalışma kapsamında ulaşılan tüm makalelerin örnekleme dâhil edilmesi uygun görülmüştür.

\section{BULGULAR}

Çalışma kapsamında 2009-2020 yılları arasında iklim değişikliği ve gıda güvenliği ile ilgili yayımlanan 32 makale çeşitli parametreler aracıllğı ile incelenmiştir. Makalelerin yayımlandığı yıllar incelendiğinde, ulaşılabilen makaleler arasında iklim değişikliği ve gıda güvenliği ile ilgili ilk makalenin 2009 yılında yayımlandığ 2014 yllında (\%21,8), en az makalenin ise 2011, 2012, 2016, 2018 ve 2019 ylllarında (\%3) yayımlandığı görülmektedir. Özellikle 2013, 2014 ve 2015 yıllarında yayımlanan makale sayılarında bir artış olduğu göze çarpmaktadır. Araştırma bulguları Tablo-1'de gösterilmektedir.

Tablo 1. İklim Değişikliği ve Gıda Güvenliği Konulu Makalelerin Yılara Göre Dağılım (n:32)

\begin{tabular}{|c|c|c|}
\hline \multicolumn{3}{|c|}{ Özellik } \\
\hline Y1l (n: 32) & $f$ & $\%$ \\
\hline 2009 & 3 & 9,3 \\
\hline 2010 & 3 & 9,3 \\
\hline 2011 & 1 & 3 \\
\hline 2012 & 1 & 3 \\
\hline 2013 & 5 & 15,5 \\
\hline 2014 & 7 & 21,8 \\
\hline 2015 & 4 & 12,5 \\
\hline 2016 & 1 & 3 \\
\hline 2017 & 3 & 9,3 \\
\hline 2018 & 1 & 3 \\
\hline 2019 & 1 & 3 \\
\hline 2020 & 2 & 6,2 \\
\hline
\end{tabular}

Makalelerin yayımlandığı dergilerin yayım alanları incelenmiştir. Makalelerin sırası ile yiyecek içecek $(\% 40,5)$, gıda güvenliği $(\% 21,8)$ ve disiplinler arası $(\% 6,2)$ konularında yayım yapan dergilerde yayımlandığı tespit edilmiştir.

Araştırma kapsamında iklim değişikliği ve gıda güvenliği konulu makalelerin yayımlandıkları dergilere göre dağılımları incelenmiştir. İlgili konu hakkında en çok yayım yapan dergiler sırası ile Food Research International (\%28), Journal of Food Hygiene and Safety $(\% 9,3)$ ve Safe Food 
$(\% 6,2)$ dergilerinde yayımlandıkları görülmektedir. Bununla birlikte makalelerin 21 farklı dergide yayımlandığı tespit edilmiştir. Araştırma bulguları Tablo 3'te gösterilmektedir.

Tablo 2. İklim Değişikliği ve Gıda Güvenliği Konulu Makalelerin Dergi Yayım Alanlarına Göre Dağılım (n:32)

\begin{tabular}{|c|c|c|}
\hline \multicolumn{3}{|c|}{ Özellik } \\
\hline Dergi Yayım Alanı (n:32) & $\mathrm{f}$ & $\%$ \\
\hline Yiyecek İcecek & 13 & 40,5 \\
\hline Gida Güvenliği & 7 & 21,8 \\
\hline Disiplinler arası & 2 & 6,2 \\
\hline İklim Değişikliği & 1 & 3 \\
\hline Doğu Asya Yiyecek Kültürü & 1 & 3 \\
\hline Et Bilimi & 1 & 3 \\
\hline Meslek Hekimliği & 1 & 3 \\
\hline Çevresel Sorunlar & 1 & 3 \\
\hline Gida Bilimi ve Teknolojisi & 1 & 3 \\
\hline Gastroentoloji & 1 & 3 \\
\hline Mühendislik & 1 & 3 \\
\hline Tarım & 1 & 3 \\
\hline Politika & 1 & 3 \\
\hline
\end{tabular}

Tablo 3. İklim Değişikliği ve Gıda Güvenliği Konulu Makalelerin Dergilere Göre Dağılımı

\section{Özellik}

\begin{tabular}{l|c|c}
\hline Dergi (n:32) & F & $\%$ \\
\hline Food Research International & 9 & 28 \\
\hline Journal of Food Hygiene and Safety & 3 & 9,3 \\
\hline Safe Food & 2 & 6,2 \\
\hline British Politics & 1 & 3 \\
\hline Plos One & 1 & 3 \\
\hline Food Sciences and Technology & 1 & 3 \\
\hline Agronomy for Sustainable Development & 1 & 3 \\
\hline Food and Chemical Toxicology & 1 & 3 \\
\hline Food Control & 1 & 3 \\
\hline Carbon Management & 1 & 3 \\
\hline Journal of East Asian Society Dietary Life & 1 & 3 \\
\hline Theory and Pratice of Meat Processing & 1 & 3 \\
\hline Egyptian Journal of Occupational Medicine & 1 & 3 \\
\hline Journal of Environmental Health Sciences & 1 & 3 \\
\hline International Journal of Advanced Research & 1 & 3 \\
\hline Maso International Journal of Food Science and Technology & 1 & 3 \\
\hline International Center for Advanced Mediterranean Agronomic Studies & 1 & 3 \\
\hline Mediterranean Journal of Social Sciences & 1 & 3 \\
\hline Journal of Gastroenterology Research & 1 & 3 \\
\hline International Journal of Advanced Research in Science and Engineering & 1 & 3 \\
\hline Trends in Food Science and Technology & 1 & 3 \\
\hline
\end{tabular}


Makalelerin sahip oldukları anahtar kelimeler incelendiğinde, toplamda 79 adet anahtar kelimeye sahip oldukları tespit edilmiştir. Nitekim 4 çalışmada anahtar kelime belirtilmemiştir. Makalelerde en sık tekrar eden anahtar kelimelerin sırası ile "İklim değişikliği" (\%30,3), "Gıda güvenliği" $(\% 17,7)$ ve "Gıda kaynaklı hastalıklar" (\%5) olduğu görülmektedir. Makalelerde toplamda 29 farklı anahtar kelime kullanıldığı belirlenmiştir. Araştırma bulguları Tablo-4'te gösterilmektedir.

Tablo 4. İklim Değişikliği ve Gıda Güvenliği Konulu Makalelerin Anahtar Kelimelere Göre Dağılımı

\begin{tabular}{|c|c|c|}
\hline \multicolumn{3}{|c|}{ Özellik } \\
\hline Anahtar Kelimeler (n: 79) & $\mathbf{F}$ & $\%$ \\
\hline İklim Değişikliği & 24 & 30,3 \\
\hline G1da Güvenliği & 14 & 17,7 \\
\hline Gıda Kaynaklı Hastalıklar & 4 & 5 \\
\hline Belirtilmemiş & 4 & 5 \\
\hline Gıda Güvenliği Yönetim Sistemi & 3 & 3,7 \\
\hline Riskler & 3 & 3,7 \\
\hline Zararlı Alg Çiçeği & 2 & 2,5 \\
\hline Gida Zinciri & 2 & 2,5 \\
\hline Taze Ürün & 2 & 2,5 \\
\hline Avrupa & 1 & 1,2 \\
\hline Ekstrem Hava Koşulları & 1 & 1,2 \\
\hline Doğal Afetler & 1 & 1,2 \\
\hline İklim Tahmini & 1 & 1,2 \\
\hline Yiyecek Politikası & 1 & 1,2 \\
\hline Politika Değişimi & 1 & 1,2 \\
\hline Yönetim & 1 & 1,2 \\
\hline Politika Paradigması & 1 & 1,2 \\
\hline Yem Üreticileri & 1 & 1,2 \\
\hline Süt Ürünleri & 1 & 1,2 \\
\hline Hayvan Sağllğg & 1 & 1,2 \\
\hline HACCP & 1 & 1,2 \\
\hline QMRA & 1 & 1,2 \\
\hline Raf Ömrü Tahmini & 1 & 1,2 \\
\hline Meta-Analizi & 1 & 1,2 \\
\hline Gida Kontrolü & 1 & 1,2 \\
\hline Gıda Üretimi & 1 & 1,2 \\
\hline Karbon Politikası & 1 & 1,2 \\
\hline Gıda Kaynaklı Tehlikeler & 1 & 1,2 \\
\hline Mikrobiyolojik Gıda Güvenliği & 1 & 1,2 \\
\hline Gıda Güvenliği Kültürü & 1 & 1,2 \\
\hline
\end{tabular}

İklim değişikliği ve gıda güvenliği konulu makalelerin atıf sayısı toplamı 1723'tür. Ortalama atıf sayısı 53,8'dir. En yüksek atıflı iki makale 138, en düşük atıflı makale 6 atıf kullanmıştır. Atıf sayılarının dağılımı incelendiğinde, 0-50 atıflı makalelerin yoğun olduğu görülmektedir. Makalelerin \%53'ü 0-50, \%34'ü 51-100 ve \%4'ü 101-150 atıf aralığında yer aldığı görülmektedir. Araştırma bulguları Tablo-5'te gösterilmektedir. 
Tablo 5. İklim Değişikliği ve Gıda Güvenliği Konulu Makalelerin Sayfa ve Atıf Sayısına Göre Dağ̆lımı

\begin{tabular}{lccc}
\hline & Özellik & & \\
\hline Atıf Sayıs1 (n: 32) & F & $\mathbf{\%}$ \\
\hline $0-50$ & 17 & 53 \\
\hline $51-100$ & 11 & 34 \\
\hline $101-150$ & 4 & 12,5 \\
\hline
\end{tabular}

İklim değişikliği ve gıda güvenliği konulu makalelerin sayfa sayısı toplamı 326'dır. Ortalama sayfa sayısı 10,1'dir. En yüksek sayfa sayılı makale 28, en düşük sayfa sayılı makale ise 3 sayfadır. Sayfa sayılarının dağılımı incelendiğinde, 0-10 sayfa sayıları aralığındaki makalelerin yoğun olduğu görülmektedir. Makalelerin \% 68,7'si 0-10, \%25'i 11-20 ve \%6,2'si de 21-30 sayfa aralığında yer aldığı tespit edilmiştir. Araştırma bulguları Tablo-6'da gösterilmektedir.

Tablo 6. İklim Değişikliği ve Gıda Güvenliği Konulu Makalelerin Sayfa Sayısına Göre Dağılımı

\begin{tabular}{lcc}
\hline & Özellik & \\
\hline Sayfa Sayısı (n: 32) & F & \% \\
\hline $0-10$ & 22 & 68,7 \\
\hline $11-20$ & 8 & 25 \\
\hline $21-30$ & 2 & 6,2 \\
\hline
\end{tabular}

Araştırma kapsamında iklim değişikliği ve gıda güvenliği konulu makalelerin araştırma yöntem bilgilerine göre dağılımları incelenmiştir. Makalelerin araştırma yaklaşımlarına göre çoğunlukla kavramsal araştırmalar olduğu tespit edilmiştir. Toplam 32 araştırmanın \%84'ü kavramsal \%16'sı ise ampirik araştırmalardan oluşmaktadır. Ampirik araştırmaların veri toplama yöntemlerine göre dağılımına bakıldığında \%60'ının anket \%40'ının ise mülakat yöntemi ile veri topladığı tespit edilmiştir. Araştırma bulguları Tablo 7'de gösterilmektedir.

Tablo 7. İklim Değişikliği ve Gıda Güvenliği Konulu Makalelerin Araştırma Yöntem Bilgilerine Göre Dağılımı

\begin{tabular}{lcclccc}
\hline \multicolumn{1}{c}{ Özellik } & & & Özellik \\
\hline Araştırma Yaklaşımı (n: 32) & F & $\%$ & Veri Toplama Yöntemi (n: 5) & F & \% \\
\hline Kavramsal & 27 & 84 & Anket & 3 & 60 \\
\hline Ampirik & 5 & 16 & Mülakat & 2 & 40 \\
\hline
\end{tabular}

Araştırma kapsamında makalelerin çok yazarlılık durumu incelenmiştir. 32 makaleye toplamda 143 yazar katkı sağlamıştır. Makale başına yazar ortalaması 4,4'tür. Makalelerin \%28'inin 5 veya daha fazla yazar tarafından, $\% 21,8^{\prime}$ inin 1 yazarlı ve $\% 21,8^{\prime}$ inin 3 yazarlı olduğu tespit edilmiştir. Araştırma bulguları Tablo 8' de gösterilmiştir.

Tablo 8. İklim Değişikliği ve Gıda Güvenliği Konulu Makalelerin Çok Yazarlılık Durumuna Göre Dağılımı

\begin{tabular}{|c|c|c|}
\hline \multicolumn{3}{|c|}{ Özellik } \\
\hline Çok Yazarlılık Durumu (n: 32) & $\mathbf{F}$ & $\%$ \\
\hline 1 Yazarlı & 7 & 21,8 \\
\hline 2 Yazarlı & 3 & 9,3 \\
\hline 3 Yazarlı & 7 & 21,8 \\
\hline 4 Yazarlı & 6 & 18,7 \\
\hline 5 veya daha fazla yazarlı & 9 & 28 \\
\hline
\end{tabular}


Ampirik araştırmaların verilerinin toplandığı ülkelere bakıldığında \%60'ının Güney Kore, \%20'sinin Hollanda ve Yeni Zelanda' dan toplandığı tespit edilmiştir. Araştırma bulguları Tablo9'da gösterilmektedir.

Tablo 9. İklim Değişikliği ve Gıda Güvenliği Konulu Makalelerin Verilerin Toplandığı Ülkelere Göre Dağılımı

\begin{tabular}{lccc}
\hline & Özellik & & \\
\hline Verilerin toplandığ $̈$ Ülkeler (n: 5) & F & $\mathbf{\%}$ \\
\hline Güney Kore & 3 & 60 \\
\hline Hollanda & 1 & 20 \\
\hline Yeni Zelanda & 1 & 20 \\
\hline
\end{tabular}

Araştırma kapsamında iklim değişikliği ve gıda güvenliği konulu makale yazarlarının çalıştığ1 kurumlara göre dağılımı incelenmiştir. İlgili konu hakkında yayım yapan yazarların çalıştığı kurumlar sirası ile Wageningen University (\%10,5), Chung-Ang University (\%7), Ghent University $(\% 5,2)$ ve University of York $(\% 3,5)^{\prime}$ tur. Toplamda 57 farklı kurum çalışanı tarafından makalelere katkı sağlanmıştır. Araştırma bulguları Tablo- 5'te gösterilmektedir.

Tablo 10. İklim Değişikliği ve Gıda Güvenliği Konulu Makale Yazarlarının Çalıştığı Kurumlara Göre Dağılımı

\begin{tabular}{|c|c|c|c|c|c|}
\hline \multicolumn{3}{|l|}{ Özellik } & \multicolumn{3}{|l|}{ Özellik } \\
\hline Yazarların Çalıştığı Kurumlar (n: 57) & $\mathbf{F}$ & $\%$ & Yazarların Çalıştığı Kurumlar & $\mathbf{F}$ & $\%$ \\
\hline Wageningen University & 6 & 10,5 & University of Edinburgh & 1 & 1,7 \\
\hline Chung-Ang University & 4 & 7 & Cairo University & 1 & 1,7 \\
\hline Ghent University & 3 & 5,2 & Keimyung University & 1 & 1,7 \\
\hline University of York & 2 & 3,5 & The University of West Indies & 1 & 1,7 \\
\hline The University of Surrey & 1 & 1,7 & Korea Health Industry Development Institute & 1 & 1,7 \\
\hline Italian National Institute for Health & 1 & 1,7 & Institute of Meat Hygiene and Technology, & 1 & 1,7 \\
\hline University of California & 1 & 1,7 & University of Hradec & 1 & 1,7 \\
\hline Catholic University of the Sacred Heart & 1 & 1,7 & University of Zaragoza & 1 & 1,7 \\
\hline $\begin{array}{l}\text { Agronomy and Crop Sciences Research and } \\
\text { Education Center }\end{array}$ & 1 & 1,7 & Duksung Women's University & 1 & 1,7 \\
\hline $\begin{array}{l}\text { Netherlands Environmental Assessment } \\
\text { Agency }\end{array}$ & 1 & 1,7 & Ministry of Food and Drug Safety & 1 & 1,7 \\
\hline Federal Institute for Risk Assessment & 1 & 1,7 & University of Limpopo & 1 & 1,7 \\
\hline $\mathrm{FAO}$ & 1 & 1,7 & Uşak University & 1 & 1,7 \\
\hline North California State University & 1 & 1,7 & Gıda Tarım ve Hayvancılık Bakanlığ1 & 1 & 1,7 \\
\hline Cardiff University & 1 & 1,7 & İstanbul University & 1 & 1,7 \\
\hline Wessex Institute of Technology & 1 & 1,7 & Firat University & 1 & 1,7 \\
\hline Public Health Agency of Canada & 1 & 1,7 & Sher-e-Kashmir University & 1 & 1,7 \\
\hline Victoria University of Wellington & 1 & 1,7 & University of Central & 1 & 1,7 \\
\hline Queens University & 1 & 1,7 & University of Guelph & 1 & 1,7 \\
\hline Chinese Academy of Agricultural Sciences & 1 & 1,7 & $\begin{array}{l}\text { Research Unit of Upgrading of Fishery and } \\
\text { Farmed Products }\end{array}$ & 1 & 1,7 \\
\hline Korea Food and Drug Administration & 1 & 1,7 & $\begin{array}{l}\text { National Oceanic and Atmospheric } \\
\text { Administration }\end{array}$ & 1 & 1,7 \\
\hline Yeungnam University & 1 & 1,7 & Renmin University of China & 1 & 1,7 \\
\hline $\begin{array}{l}\text { Sir Alister Hardy Foundation for Ocean } \\
\text { Science }\end{array}$ & 1 & 1,7 & Risk Sciences International & 1 & 1,7 \\
\hline Kangwon National University & 1 & 1,7 & Kunsan National University & 1 & 1,7 \\
\hline
\end{tabular}




\section{TARTIŞMA, SONUÇ ve ÖNERILLER}

Bibliyometrik çalışmalar, bir bilim dalında ya da bir çalışma sahasında yapılmış eserlerin değerlendirilip sınıflandırıldığı ve durum tespitinin gerçekleştirildiği çalışmalardır (Şahin ve diğerleri, 2018). Bu bağlamda yapılan çalışmada gıda güvenliği ve iklim değişikliği konulu hakem dergili makaleler incelemeye tabi tutulmuştur. Çeşitli veri tabanları (EBSCO Host, JSTOR, SageJournal, Scopus, Springer Link, Wiley Online Library gibi) üzerinden erişim sağlanan 32 makale araştırma kapsamına dâhil edilmiştir. Çalışma, gıda güvenliği ve iklim değişikliği ile ilgili alanyazının durumunu, gelişimini ve sorunları hakkında değerlendirme yapma ve yorumlama imkânı sağlamaktadır.

Haunschild, Bornmann ve Marx (2016) iklim değişikliği konulu makalelerin bibliyometrik incelemesini 1980 yılından itibaren başlatmışlardır. Bununla birlikte DaMing (2012) çalışmasından gıda güvenliği konulu makalelerin bibliyometrik incelemesini 2002 yılında başlatmıştır. Bu çalışmada ise gida güvenliği ve iklim değişikliği ile ilgili ilk makalelere 2009 yılında rastlanılmıştır. Makale sayıları 2013-2014-2015 yıllarında yükselse de sonrasında tekrardan 2013 öncesi seviyelerine gerilemiştir. İklim değişikliği ve gıda güvenliği birbirleri ile oldukça ilgili konular olmalarına (Tirado, Clarke, Jaykus, McQuatters ve Frank, 2010) ve literatürde uzun süredir çalışılmış olmalarına rağmen, yazarların bu iki konuyu ayrı bir biçimde çalışma eğiliminde oldukları ortaya çıkmaktadır. Bu sonuca destek olabilecek bir başka bulgu ise makale sayılarında görülmektedir. Haunschild ve diğerleri (2016)'nin yaptıkları çalışma kapsamında iklim değişikliği ile ilgili 222,060 makale taranırken, DaMing (2012)'in çalışmasında gıda güvenliği ile ilgili 8203 makale incelemeye alınmıştır. Bu çalışmada ise erişilebilen makale sayısı sadece 32'dir. Sonuç olarak araştırmacıların iklim değişikliği ve gıda güvenliği konulu yayımlara daha az ilgi gösterdikleri söylenebilir.

Araştırma kapsamında makalelerin kullandıkları anahtar kelimeler incelenmiştir. Makalelerin en çok kullandıkları anahtar kelimelerin iklim değişikliği ve gıda güvenliği olduğu sonucuna ulaşılmıştır. Araştırma kapsamına dâhil edilen makalelerin direkt olarak bu iki konuyu inceliyor olması bu durumun bir nedeni olarak gösterilebilir. Bununla birlikte çalışma Haunschild ve diğerleri (2016)'nin çalışması ile benzerlik göstermektedir. Ayrıca makalelerin toplamda 29 farklı anahtar kelime kullandıkları tespit edilmiştir.

Makalelerin yayım alanları incelendiğinde en çok yiyecek içecek alanında yayım yapan dergilerde makale yayımlandığı görülmektedir. Bu durumun iklim değişikliğinin gıda güvenliği ile direk ilişkisini inceleyen yayımlar nedeni ile oluştuğunu söylemek mümkündür. Makalelerin yayımlandığı dergiler de bu durumu destekler niteliktedir. Food Research International, Journal of Food Hygiene and Safety ve Safe Food konu ile ilgili en çok yayım yapan dergiler olarak göze çarpmaktadır. Çalışmaların çoğunun 0-50 atıf yaptıkları ve çoğunun 0-10 sayfa aralığında yayımlandıkları görülmektedir. Bununla birlikte araştırmaların büyük bir çoğunluğu kavramsal araştırmalardır. Bu bağlamda yayımlanan makalelerin ampirik araştırmalardan ziyade kavramsal araştırmalar olduğu görülmektedir. Araştırmaların çoğunluğu 5 ya da daha fazla yazar tarafından gerçekleştirilmiştir. Bununla birlikte tek yazarlı araştırmalar da bulunmaktadır. Ampirik araştırmalarda veri toplama tekniği olarak anket ve mülakat kullanılmış, veri toplanan yer olarak ise yoğun olarak Güney Kore tercih edilmiştir.

Makale yazarlarının çalıştıkları kurumlar incelendiğinde en fazla yayımın Wageningen University, Chung-Ang University, Ghent University kurumlarında çalışan araştırmacılar tarafından yapıldığı görülmektedir. Bununla birlikte 45 farklı kurumda çalışan yazarlar tarafından ilgili alanyazına katkı sağlanmıştır. En çok yayım ise Belçika ve Güney Kore kurumlarında çalışan yazarlar tarafından yayımlanmıştır. Literatür incelendiğinde hem üniversite hem de ülke bazından en fazla yayım sahibi olan ülkenin Amerika Birleşik Devletleri 
olduğu Hollanda'nın da aralarında bulunduğu Avrupa ülkelerinin ise bunu izlediği görülmektedir (Shen, Wei ve Sheng, 2021; Polat, Düzgün ve Yeşiltaş, 2019; Haunschild, Bornmann ve Marx, 2016; Sweilah, 2020; Sweilah, 2020). Bu ülkelerin sanayi açısından gelişmiş olmakla birlikte tarım konusunda da lider konumda olmayı sürdürmeleri, teknoloji ile olan yakın bağları sebebi ile her ne kadar sanayi toplumu olsalar da iklim değişikliği ve gıda güvenliği konusunda öncü durumda olmalarını açıklayabilir. Bu açıdan bakıldığında temelde bir tarım toplumu olan Türkiye' de, akademisyenlerin iklim değişikliği ve gıda güvenliği konularında daha fazla bilimsel çalışma içerisinde bulunması önerilebilir. Bu durum, uluslararası normlara uygunluk sağlanması ve halk sağlığının korunup sürdürülebilmesi açısından önemlidir.

Çalışma hem araştırmacılara hem de ilgili yazına çeşitli katkılar sunmaktadır. İklim değişikliği ve gıda güvenliği konusunda çalışma gerçekleştirecek araştırmacılar hangi konularda çalışma yapılabileceği konusunda ilgili çalışmadan yararlanabilir ve bu sayede çalışmalarını tasarlayabilirler. Araştırmacılar gida güvenliği ve iklim değişikliği konulu makalelerde hangi araştırma yöntemlerinin kullanıldığı, hangi veri toplama yöntemine başvurulduğu ile ilgili detaylı bilgi sahibi olabilirler. Uluslararası literatürde yayımlanan ve veri tabanları üzerinden erişimi sağlanan makalelerin incelenmesi araştırmanın sınırlılı̆̆ını oluşturmaktadır. Bu bağlamda ileriki araştırmalarda bu makalelerin yanı sıra ulaşılabilen farklı makaleler ile kitap, kitap bölümü veya bildiriler gibi eserler de incelemeye dâhil edilerek araştırma tekrar edilebilir. Araştırmanın diğer bir sınırlılığı, incelenen makalelerin iklim değişikliği ve gıda güvenliği konuları ile sınırlı tutulmasıdır. Bu açıdan ileriki çalışmalarda gerek iklim değişikliği gerekse gıda güvenliği makaleleri genelinde bibliyometrik araştırmalar gerçekleştirilebilir.

\section{KAYNAKÇA}

Altürk, A. (2018). Türkiye turizm literatürünün durumu: uluslararası dergi makalelerinin bibliyoemetrik analizi. (Yayımlanmamış yüksek lisans tezi), Batman Üniversitesi, Batman.

Barrios, M., Vilagines, A., Olle, C., and Somoza, M. (2008). A bibliometric study of psychological research on tourism. Scientometrics, 77(3), 453-467.

Ceyhun Sezgin, A. E. (2020). Yiyecek İçecek İşletmelerinde Gıda Güvenliği ve Hijyen Uygulamaları. S. Akar Şahingöz, ve T. Süren içinde, Mutfak Uygulamaları (s. 169-210). Ankara: Detay Yayıncilık.

Çiçek, D., ve Kozak, N. (2012). Anatolia: turizm araştırmaları dergisinde yayımlanan hakem denetimli makalelerin bibliyometrik profili. Türk Kütüphaneciliği, 26(4), 734-756.

DaMing, C. (2012). A bibliometric analysis of the scientific literature on food safety research. Journal of Food Safety and Quality, 3(2), 145-150.

EC-DGE (European Commission-Directorate General Environment) (2005). The Impacts and Costs of Climate Change, http://ec.europa.eu/environment/ climat/pdf/final_report2.pdf adresinden alındı.

Güzeller, C. O., ve Çeliker, N. (2017). Geçmişten Günümüze Gastronomi Bilimi: Bibliyometrik Bir Analiz. Journal of Tourism and Gastronomy Studies, 5(2), 88-102.

Haunschild, R., Bornmann, L., and Marx, W. (2016). Climate change research in view of bibliometrics. Plos One, 11(7), 1-19.

https://www.ipcc.ch/site/assets/uploads/2018/02/AR5_SYR_FINAL_SPM.pdf adresinden alındı Erişim Tarihi: 27.02.2021 
Kasemodel, M. G., Makishi, F., Souza, R. C., and Silva, V. L. (2016). Following the trail of crumbs: A bibliometric study on consumer behavior in the Food Science and Technology field. International Journal of Food Studies, 5(1), 73-83.

Polat, E., Düzgün, E., ve Yeşiltaş, M. (2019). İklim değişikliğinin turizme etkisini belirlemeye yönelik hazırlanan lisansüstü tezlerin bibliyometrik profili. Gümüşhane Üniversitesi Sosyal Bilimler Enstitüsü Elektronik Dergisi, 10(Ek Say1), 240-249.

Pritchard, A. (1969). Statistical bibliography or bibliometrics? Journal of Documentation, 348-349.

Sengupta, I. N. (1992). Bibliometrics, informetrics, scientometrics and librametrics: an overview. Libri, 42, 75-98.

Shapiro, F. R. (1992). Origins of bibliometrics, citation indexing, and citation analysis: the neglected legal literature. Journal Of The American Society For Information Science, 43(5), 337-339.

Shen, C., Wei, M., and Sheng, Y. (2021). A bibliometric analysis of food safety governance research from 1999 to 2019. Food Science Nutrition, 1-19.

Sweileh, W. M. (2020a). Bibliometric analysis of peer-reviewed literature on climate change and human health with an emphasis on infectious diseases. Globalization and Health, 16(1), 1-17.

Sweileh, W. M. (2020b). Bibliometric analysis of peer-reviewed literature on food security in the context of climate change from 1980 to 2019. Agriculture and Food Security, 9(11), 1-15.

Şahin, E., Akdağ, G., Çakıcı, C., ve Onur, N. (2018). Gastronomi ve mutfak anabilim dallarında yayınlanan tezlerin bibliyometrik analizi. Güncel Turizm Araştırmaları Dergisi, 2(1), 30-41.

Tirado, M. C., Clarke, R., Jaykus, L. A., McQuatters-Gollop, A., and Frank, J. M. (2010). Climate change and food safety: a review. Food Research International, 43(7), 1745-1765.

Wahyuni, H., Vanany, I., and Ciptomulyono, U. (2019). Food safety and halal food in the supply chain: review and bibliometric analysis. Journal of Industrial Engineering and Management, 12(2), 373-391.

Wang, Z., Zhao, Y., and Wang, B. (2018). A bibliometric analysis of climate change adaptation based on massive research literature data. Journal of Cleaner Production, 199,1072-1082.

Webster, M. (1985). Webster's ninth new collegiate dictionary. Springfield: Merriam-Webster Inc.

Wu, F., Geng, Y., Tian, X., Zhong, S., Wu, W., Yu, S., and Xiao, S. (2018). Responding climate change: A bibliometric review on urban environmental governance. Journal of Cleaner Production, 344-354.

Yılmaz, G. (2017). Restoranlarda bahşiş ile ilgili yayınlanan makalelerin bibliyometrik analizi. Seyahat ve Otel İşletmeciliği Dergisi, 14(2), 65-79.

Zyoud, S. H., and Fuchs-Hanusch, D. (2020). Mapping of climate change research in the Arab world: a bibliometric analysis. Environmental Science and Pollution Research, 27, 3523-3540. 